\title{
BÉCQUER, PRECEDENTE DE LA MODERNIDAD
}

\author{
Miguel González Dengra \\ UNED. Úbeda
}

\section{RESUMEN}

A partir de la definición que de Gustavo Adolfo Bécquer hace el Diccionario Oxford de literatura española e hispanoamericana como auno de los mayores poetas del romanticismo español», se realiza un análisis de cuáles han sido las circunstancias que han hecho que la crítica literaria y los propios poetas españoles hayan ido variando sus posiciones respeto del poeta sevillano, dejando de ser considerado autor exclusivamente romántico para, sobre todo después de los escritores del 98, ser tenido como precursor de la modernidad.

El Diccionario Oxford de literatura española e hispanoamericana inicia el artículo «Bécquer» con el siguiente enunciado: «Uno de los mayores poetas del romanticismo español" '. Esta afirmación, que pudiera ser asumida por cualquier iletrado medio español y que, durante bastantes años, ha sido para casi todos una verdad incuestionable, hoy apenas nadie puede asumirla. Hoy, cuando Bécquer ha dejado de ser cola del romanticismo para pasar a ser cabeza de la modernidad, extraña más que el mencionado Diccionario Oxford mantenga esta aseveración; y extraña más si tenemos en cuenta que ha sido preci-

I Edición al cuidado de WARD, PHILIP (1984), Barcelona, Crítica, p. 86. 
samente el hispanismo inglés, a partir de Sebold ${ }^{2}$, Brown ${ }^{3}$ y Shaw ${ }^{4}$, el que, al cambiar las fechas de nuestro romanticismo, ha situado a Bécquer fuera de él. Primero, romántico; más tarde, romántico tardío; después, post-romántico; para terminar hoy (y no sabemos bien si acaso mañana) de aurora de lo moderno. El camino no ha sido fácil. Se diría que la golondrina becqueriana ha cambiado de nido cada primavera crítica.

Y el camino no ha sido fácil porque los datos inmediatos, siempre externos, que manejan, tienden, aparentemente, a romantizar su figura; tal vez porque el concepto, popular medio del romanticismo tampoco sea hoy el adecuado: la tuberculosis, las desgracias sentimentales, la estrechez material, las desdichas maritales, todo. Cuanto más se investiga, más se va fijando un daguerrotipo romántico $\longrightarrow$ que nosotros creemos que lo es-. Todo lo que conocemos de Bécquer, en su apariencia externa, nos lleva hacia la niñez de nuestras abuelas: vestidos de blanco de moaré y anchos cinturones de lazo, tirabuzones, toto impoluto sobre la cabellera, aspergios de cualquier preludio y la voz inocente y blanca que declama la rima que había emocionado a su madre en su pasada juventud y que, tal vez, emocionaba la suya.

Este Bécquer, que ha existido, parangón romántico, no existe ya. Existe otro Bécquer. El cambio o trueque se ha producido en el terreno de la crítica. El Bécquer romántico, como todo el romanticismo, no pasa más allá de los escritores del 98. Lo que hoy consideramos el gran Bécquer, el Bécquer dintel de la poesía moderna, nace a través de otro gran poeta: Juan Ramón Jiménez. Lo que hoy nos queda de Bécquer no son sus poesías, sino una poética; no unos poemas, aunque también nos queden, sino un método poético, una nueva tradición.

Este giro, esta inversión becqueriana, ocurre, como he señalado, en el terreno de la crítica literaria, encabezada por el hispanismo británico; pero, al mismo tiempo, en el campo de la poesía española, en la misma estructura interna del vivir poético español. Veamos cómo.

En primer lugar, unas precisiones cronológicas.

Como es bien sabido, los treinta y cuatro años de vida de Bécquer discurren entre 1836 y 1870 . En vida sólo publicó un libro, a los 22 años, y sólo el

2 Sebold, Russell P. (1973), «El incesto, el suicidio y el primer romanticismo español», Hispanic Review, XLI, pp. 669-692;

- (1974) Cadalso: el primer romántico europeo de España, Madrid, Gredos.

3 Brown, Rica (1963), Gustavo Adolfo Bécquer en dos tiempos, Barcelona, Aedos.

4 Shaw, Donald L. (1963), «Toward and understanding of Spanish Romanticism», Modern Language Review, LVIII, pp. 190-195.

- (1968), «The Antic-romantic reaction in Spain», Modern Language Review, LXIII, pp. 606-611. 
primer tomo. Se trata de su Historia de los templos de España. El resto es periodismo, hasta el extremo que quizás los contemporáneos, Bécquer mismo, no podría(n) verlo(se) como poeta, se hubiera(n) sorprendido. En 1871, cuando ya Bécquer es un año huésped de las sombras, aparecen las Rimas. Su éxito es inmediato, pero lento. Aquellos versos, que Núñez de Arce consideró «suspirillos germánicos», fueron abriéndose camino, pero no como una llamarada instantánea, sino como una ascua lenta e íntima. Fueron apareciendo las fuentes y el poeta sevillano empezó a aparecer acompañando a los Heine, Byron, Musset. Huellas indudables que explican momentos de sus versos y, salvo la primera, sin importancia alguna para la tonalidad global de la obra becqueriana. Todo responde nada más que a una mala ubicación de Bécquer en la historia de la literatura española del siglo XIX.

Hoy, cuando hemos recuperado para el romanticismo totalmente a Cadalso y replanteada la historia literaria de final del siglo XVIII, y cuando ya el regreso de los exiliados no tiene más que un valor anecdótico, no se puede colocar a Bécquer alegremente como coda del romanticismo español.

Si precisamos más las fechas, veremos que Bécquer nace un año después del Don Álvaro ${ }^{5}$ del duque de Rivas, y nace escoltado, a un lado, por El trovador ${ }^{6}$ de García Gutiérrez, pero, a otro, por Picwick ${ }^{7}$ de Charles Dickens. Y muere cuando comienza el reinado de Amadeo de Saboya ${ }^{8}$ y se publica en volumen La Fontana de Oro ${ }^{9}$ de Pérez Galdós. Como antes de que Bécquer elaborara un solo verso ya se han publicado Las flores del mal ${ }^{10}$ de Baudelaire y como antes que sus versos fueran fijados en el primer texto ya se ha editado Los poemas saturnianos ${ }^{11}$ de Verlaine, nada impide pensar que Bécquer conocía los movimientos de renovación poética en ebullición en Europa, o que, si no los conocía de modo inmediato o total, su genialidad poética le hizo estar a la altura de las circunstancias de la modemidad. Una modernidad que, como todas, tiene sus raíces en el pasado.

Si estas precisiones cronológicas han servido para colocarnos a Bécquer en las puertas de lo que con harta imprecisión se llama modernidad (pero que es término que conviene), puesto que alguien tendría que interpretar en la historia literaria - ya que toda historia no admite hiatos ni, acaso, soluciones de

5 Estrenado el 22 de marzo de 1835.

- Estrenado el 1 de marzo de 1836.

7 Publicado en periodicos entre marzo de 1836 y octubre de 1837.

${ }^{8}$ Amadeo de Saboya llegó a España el 31 de diciembre de 1870. Su reinado apenas durará tres años.

9 Publicada en folletín entre 1867 y 1868; y en volumen en 1870 .

10 Se publicaron el 25 de junio de 1857 .

"Publicados el año 1866. 
continuidad-, lo que ya aparece con menos evidencia es que el poeta sevillano se adelantó mucho y que los motivos por los que se adelantó los dejó expresamente dichos.

Hace unos años, Umberto Eco, en sus Apostillas a El nombre de la rosa, ha escrito que «tanto Joyce como Eliot me habían enseñado que el arte es la huida de la emoción personal» ${ }^{12}$, lo que es, formulado de otro modo, el viejo principio de que "cuanto más impersonal, más humano» que ha guiado todo el arte moderno en cualquiera de sus manifestaciones. El arte de la modernidad, pues, al menos desde esta perspectiva, se opone al fervor de los románticos, a ese romanticismo de plaza larga o escenario desde donde el vate romántico (larga melena, chalina, gestos distendidos de grandilocuencia) nos cuenta las penas, los amores, las desdichas de nuestros antepasados o de los contemporáneos situados en los aledaños de la sociedad. Pero no se opone a todo ni, tal vez, al mejor, romanticismo. Wordsworth, en el prólogo a sus $\mathrm{Ba}$ ladas, dice, entre otras cosas: «poetry is the spontaneous overflow of powerful feelings: it takes its origin from emotion recollected in tranquility» ${ }^{13}$. Este aserto, tan poco romántico en apariencia, nos indica que al acercarnos a los fenómenos, por compactos y sólidos que aparezcan a nuestra consideración, e ir distinguiendo matices, vemos como cada época lleva en sí las larvas de su destrucción.

Bien es cierto que Wordsworth es un poeta inglés con poca resonancia en el estallido de nuestro romanticismo, pero no es menos cierto que la obra de Wordsworth es de 1800 , que fue difundida en nuestra sociedad y que Bécquer pudo perfectamente conocerla. La conociera o no, coincidio con ella. En la III Carta desde mi celda, tras describir un paisaje, el poeta afirma:

Después que hube abarcado con una mirada el conjunto de aquel cuadro, imposible de reproducir con frases, siempre descoloridas y pobres, me senté en un pedrusco, lleno de esa emoción sin ideas que experimentamos siempre que una cosa cualquiera nos impresiona profundamente y parece que nos sobrecoge por su novedad o por su hermosura. En esos instantes rapidísimos, en que la sensación fecunda la inteligencia y allá en el fondo del cerebro tiene lugar la misteriosa concepción de los pensamientos que han de surgir algún día evocados por la memoria, nada se piensa, nada se razona, los sentidos todos pa-

12 ECO, UMBerto (1984), Apostillas a El nombre de la rosa, Barcelona, Lumen, p. 40.

13 «La poesía es el desbordamiento espontáneo de poderosos sentimientos: tiene su origen en la emoción recordada en la tranquilidad», en Wordsworth, Preface to Lyrical Balladas with Pastoral and Other Poems. Cito por The Norton Anthology of English Literature, vol. II, $4^{`}$ edición, Nueva York-Londres, 1979, p. 173. 
recen ocupados en recibir y guardar la impresión que analizarán más tarde ${ }^{14}$.

Años más tarde, en la II Carta literaria a una mujer, discurriendo sobre el concepto de inspiración Bécquer opinaba así:

Yo no niego que suceda así. Yo no niego nada; pero, por lo que a mí me toca, puedo asegurarte que cuando siento no escribo. Guardo, sí, en mi cerebro escritas, como en un libro misterioso, las impresiones que han dejado en él su huella al pasar; estas ligeras y ardientes hijas de la sensación duermen allí agrupadas en el fondo de mi memoria hasta el instante en que, puro, tranquilo, sereno y revestido, por decirlo así, de un poder sobrenatural, mi espíritu las evoca, y tienden sus alas transparentes, que bullen con un zumbido extraño, y cruzan otra vez a mis ojos en una visión luminosa y magnífica.

Entonces no siento ya con los nervios que se agitan, con el pecho que se oprime, con la parte orgánica y material que se conmueve al rudo choque de las sensaciones producidas por la pasion y los afectos; siento, sí, pero de una manera que puede llamarse artificial; escribo como el que copia de una página ya escrita; dibujo como el pintor que reproduce el paisaje que se dilata ante sus ojos y se pierde entre las brumas de los horizontes.

Todo el mundo siente.

Sólo a algunos seres les es dado el guardar, como un tesoro, la memoria viva de lo que han sentido.

Yo creo que éstos son los poetas. Es más: creo que únicamente por esto lo son ${ }^{13}$.

Nada más lejos del apasionamiento romántico. Bécquer coincide bastante con Wordsworth: la inspiración se hace lenguaje a través del recuerdo, como muy bien ha estudiado Jorge Guillén. Este último vio claramente como el poeta sevillano «confiado a emoción sin ideas, aguarda que el presente se transforme en pasado cuando la memoria lo llame» ${ }^{16}$, anticipándose así a Proust y a tantas parcelas del arte moderno.

Así pues, nos encontramos con dos Bécquer. Un Bécquer primero, el poeta romántico, que todavía hoy pervive entre en gran público, en bastantes tex-

14 Becouer, Gustavo Adolfo,(1942) Obras completas, Madrid, Aguilar, pp. 465-466.

15 Bécquer, op. cit., p. 630-631.

16 GUILLEN, JORGE, «Lenguaje insuficiente: Bécquer o lo inefable soñado», en (1972) Lenguaje y poesía, Madrid, Alianza Editorial, pp. 113-141. La cita se encuentra en la página 123. 
tos, hasta el extremo de poderse presentar, tal vez, en sinonimia cuasi perfecta Bécquer y romanticismo. $Y$ un Bécquer segundo, alejado del romanticismo y que representa lo contrario. A pesar de todo y de su popularidad, el Bécquer primero es el Bécquer que él mismo no quiso ser.

La historia sentimental que las Rimas describen se ha tomado como una especie de autobiografía - amor expectante, amor cumplido, amor desdichado ${ }^{17}$ - y todos hemos llegado alguna vez a convencernos de que las Rimas eran, en buena parte, una autobiografía, pero olvidando, para ello, que el orden de las Rimas es absolutamente aleatorio, que Bécquer no interviene en su ordenación y que el poeta no nos transmite la emoción, sino el recuerdo de la emoción. Este recuerdo de la emocion, tan en consonancia con Wordsworth, era la esencia misma del ser del poeta, como reconoce en el último texto que acabo de citar y en este otro texto, mucho más difundido, que pertenece al Prólogo que el poeta escribió para la obra de su amigo Ferrán:

Hay una poesía magnifica y sonora; una poesía hija de la meditación y el arte, que se engalana con todas las pompas de la lengua, que se mueve con una cadenciosa majestad, habla a la imaginación, completa sus cuadros y la conduce a su antojo por un sendero desconocido, seduciéndola con su armonía y su hermosura.

Hay otra natural, breve, seca, que brota del alma como una chispa eléctrica, que hiere el sentimiento con una palabra y huye, desnuda de artificio, desembarazada dentro de una forma libre, despierta, con una que las toca, las mil ideas que duermen en el océano sin fondo de la fantasía.

La primera tiene un valor dado: es la poesía de todo el mundo.

La segunda carece de medida absoluta, adquiere las proporciones de la imaginación que impresiona: puede llamarse la poesía de los poetas ${ }^{18}$.

La primera es una melodía que nace, se desarrolla, acaba y se desvanece.

La segunda es un acorde que se arranca de un arpa, y se quedan las cuerdas vibrando con un zumbido armonioso.

Cuando se concluye aquélla, se dobla la hoja con un suave sonrisa de satisfacción.

Cuando se acaba ésta, se inclina la frente cargada de pensamientos sin nombre.

\footnotetext{
17 En cierto modo, esta secuencia amorosa que pueden describir las Rimas aparece también en otros autores; valga como ejemplo los libros de Pedro Salinas La voz a ti debida, Razón de amor y Largo lamento.

${ }^{18}$ El subrayado es mío.
} 
La una es el fruto divino de la unión del arte y de la fantasía.

La otra es la centella inflamada que brota al choque del sentimiento y la pasion ${ }^{19}$.

Queda, pues, clara la dicotomía: hay una poesía de todo el mundo y hay una poesía de los poetas. Naturalmente, y de modo obvio, Bécquer quería que su propia obra se incluyera en el segundo grupo. De aquí la renuncia a la difusión de sus propios versos; de aquí ese transformar el discurso en confidencia que singulariza la obra de Bécquer. Pero si hay dos poesías, habrá también dos públicos: todos los demás y los poetas; la poesía de todo el mundo y la de los poetas. Para estos últimos escribió Bécquer, pero su genialidad hizo que, aunque mal interpretado, los otros, los demás, también encontrarán en él un remanso de espíritu. Nunca sabremos si fue Bécquer consciente de ello. Sí que fue consciente de los dos tipos de poesía y de los dos tipos de público, de que él escribe para los poetas y de que su obra empezó a difundirse a través de los de demás, de los no poetas. Pero, antes de seguir adelante, ¿continuaremos aún teniendo a Bécquer mal colocado en la cronología?

Porque podemos verlo como un fruto tardío más de la cultura española. Cuando nace, el romanticismo está ya triunfando; cuando escribe, ya lo ha hecho y está, tal vez, en su atardecer. Sería así Bécquer ese último resplandor, ese fruto tardío, que tanto distingue a nuestra cultura y que Menéndez Pidal lo señaló como característica habitual y permanente de la misma. Pero no olvidemos que Fernán Caballero y Valera han gozado del triunfo antes que Bécquer escriba, que Alarcón y Pereda son sus contemporáneos en el difícil menester de publicar, que Pérez Galdós está ya ahí. No olvidemos que en todo momento histórico siempre confluyen lo que acaba, lo que goza del fervor popular, lo que nace. Que hay siempre un cruce intergeneracional. Bécquer, como todos, está ahí. Y entonces, que triunfaba en aquel instante, obsesionada por las ideas, vea en Bécquer, obsesionado por el sentimiento, un poeta romántico es natural. Siempre se ve antes la cáscara que la almendra.

Habría que esperar a que aquellos para quienes había escrito lo redescubrieran; es decir, lo vieran de otra manera, lo interpretaran y se sirvieran de él. Este momento llegó con Juan Ramón Jiménez y, también, antes, con Rubén Darío ${ }^{20 .}$

Evidentemente fue Juan Ramón Jiménez quien nos rescató a Bécquer, al Bécquer que todos admiramos, al Bécquer mentor de toda nuestra poesía contemporánea. Fue Juan Ramón Jiménez el que nos hizo a Bécquer.

19 Bécquer, op. cit., pp. 647-648.

20 Rubén Dario llegó a titular un libro primerizo salido de su pluma de la siguiente forma: $R \boldsymbol{i}$ mas y abrojos (1887), en clara alusión y adhesión al poeta sevillano. 
Porque se parte de un error de apreciación excesivamente común: cualquier lector entiende a Bécquer. Hoy sabemos que esto no es cierto. Los trabajos de Bousoño han mostrado la difícil técnica de las Rimas y su anticipación a los procedimientos de la poesía contemporánea ${ }^{21}$. Ocurre que se analizan los efectos, pero no las causas de esos efectos, y esa ingenuidad y esa naturalidad son el resultado de una técnica complejísima, lejana de aquella afirmación de que en las Rimas no hay más arte que el imprescindible. En las Rimas hay arte, mucho arte, hay un nuevo arte y cuando se descubrió ese nuevo arte, la poesía española entró en una nueva tradición, la becqueriana, que reemplaza a la que, durante más de cuatrocientos años, había prosperado en nuestra lírica, la tradición garcilasista. Y fue Juan Ramón Jiménez quien primero se proclamó becqueriano, arrastrando tras él a la poesía española contemporánea (de lo que él mismo tuvo conciencia). Su trabajo «Dos aspectos de Bécquer», incluido en su libro Política poética, lo finaliza así:

Termino hoy diciendo lo que tanto he dicho y repetiré siempre (hay que repetir siempre esto a las distintas jeneraciones poéticas de habla española): que con Bécquer, libre y nuevo, empieza en España e Hispanoamérica la poesía moderna... y la modernista, como lo prueba el hecho de que Bécquer no ha cambiado de lugar en todo el tiempo transcurrido. Y que el hermoso acercamiento espiritual de España y de estos países de lengua española, que luego realiza el modernismo (lo indiqué en la segunda lectura), acercamiento que nada pudo promover sino la poesía, viene ya con la simpatía profunda con que Bécquer imanta a los mejores de los entonces jovenes poetas hispanoamericanos que presajiaban nuestro siglo ${ }^{22}$.

Juan Ramón vio en Bécquer, en el lirismo becqueriano, una confidencia apasionada, un predominio de la pasión sobre la razón, y una nueva forma: la asonancia y todo aquello que produce una nueva tradición. En una evocación poética introducida en Españoles de tres mundos, Juan Ramón Jiménez se dirige a Bécquer, al cual supone vivo en una ensoñación, y le dice:

Su modernidad no está, Bécquer, le dije, en aquellos apuntes para poemas didácticos que usted lamenta haber perdido; como no estaba la de André Chenier, que los llegó a realizar, en sus odas a... Está

2 Bousoño, CARlos, «Los conjuntos paralelísticos de Bécquer», en Alonso, D. y Bousoño, C., (1970), Seis calas en la expresión literaria española, Madrid, Gredos, 3* edición, pp. 177-226.

- (1970) Teoría de la expresión literaria, Madrid, Gredos, 5 edición.

22 Jiménez, Juan Ramón, (1982), Política poética, Madrid, Alianza Editorial, pp. 364-365. 
en sus rimas impresionistas de amor, flores eternas sin anterior apunte. Como era profundo su corazón estando usted de pie, al tenderse usted en la tierra para su sueño metamorfósico se hizo largo, llegó hasta nosotros. $Y$ ahora, al volver usted, se lo encuentra en nuestras almas ${ }^{23}$.

Esta tradición poética, que en Bécquer se inicia y en Juan Ramón Jiménez se hace conciencia literaria, dura todavía, aún cuando no en todo momento fuera reconocida por todos (más adelante veremos como algunos autores, entre ellos Unamuno y d'Ors, no comprenden al Bécquer segundo, al Bécquer que escribe para los poetas). Su momento álgido es con los poetas del 27 . Se podrían ofrecer testimonios y alusiones de todos los autores del grupo; baste con el siguiente recordatorio: la colección de poemas que publica Luis Cernuda en 1934 lleva por título Donde habite el olvido, que es el penúltimo verso de la Rima $L X V I$, que, a continuación, transcribo:

\author{
¿De dónde vengo?... El más horrible y áspero \\ de los senderos busca. \\ Las huellas de unos pies ensangrentados \\ sobre la roca dura; \\ Los despojos de un alma hecha jirones \\ en las zarzas agudas, \\ te dirán el camino \\ que conduce a mi cuna. \\ ¿Adónde voy? El más sombrío y triste \\ de los páramos cruza; \\ valle de eternas nieves y de eternas \\ melancólicas brumas. \\ En donde esté una piedra solitaria \\ sin inscripción alguna, \\ donde habite el olvido, \\ allí estará mi tumba.
}

Miguel J. Flys ha señalado como, en Donde habite el olvido, Cernuda se decanta «por la forma y el tono de la lírica becqueriana» ${ }^{24}$.

Pero las cosas, cuando se viven, no tienen la claridad que la historia les presta. Y vamos a verlo ahora en un doble episodio de la crítica del poeta sevillano.

2.3 Jiménez, JuAN RAMón, (1969), "Gustavo Adolfo Bécquer», en Españoles de tres mundos, Madrid, Aguilar, p. 318.

24 Cernuda, Luis (1985), La realidad y el deseo, edición a cargo de Miguel J. Flys, Madrid, Castalia, p. 57. 
Los poetas del 27 se proclaman becquerianos, pero del Bécquer segundo. Los hombres del 98 aman al Bécquer primero. Unamuno escribe un libro de poemas, Teresa, con poemas como éste:

Te recitaba Bécquer... Golondrinas refrescaban tus sienes al volar; sobre tu tierra vuelan sin cesar.

Las mismas que al Señor de la corona espinas le quitaron al azar; las mismas que me arrancan las espinas del corazón, que se me va a parar.

Golondrinas que vienen de tu campo trayéndome recuerdos al pasar y cuya sombra acarició la yerba bajo que has ido al fin a descansar ${ }^{25}$.

Este libro es de 1924, en los inicios de la renovación poética española que se lleva a la práctica de la mano de Bécquer, a través de Juan Ramón Jiménez. En la presentación que simula Unamuno para el libro Teresa, don Miguel escribe lo siguiente:

Y por mi parte, cuando me envío la rima 13, en que comentaba un hai-kai seudojaponés de Eugenio d'Ors, le escribí ésta:

Volverán las oscuras golondrinas...

¡Vaya si volverán!

Las románticas rimas becquerianas

gimiendo volverán.

Volverán los gastados suspirillos;

la vida los traerá...

$\mathrm{y}$ las muchas pueblerinas

de nuevo los dirán.

Mas los fríos refritos ultraístas

hechos a puro afán,

los que nunca arrancaron una lágrima,

ésos no volverán ${ }^{26}$.

Vemos así, pues, que Unamuno ataca a los renovadores poéticos, poniéndoles por delante la figura de Bécquer, de la que ellos partían: dos Bécquer distintos se enfrentaban entre sí.

25 Unamuno, Miguel de (1958), Teresa, en Obras completas, Madrid, Afrodisio Aguado, vol. XIV, p. 309.

26 UNAMUNO, op. cit., pp. 274-275. 
Pero aún hay más. En ese momento de lucha que el arte moderno lleva a cabo para imponerse (en aquella mal llamada lucha por la deshumanización del arte), hay críticos que toman partido por el arte nuevo y otros que permanecen con el antiguo. Uno de éstos fue Eugenio d'Ors. Cuando los nuevos poetas se adelantaron a calificar a Bécquer, d'Ors, que tenía muy bien aprendido el Bécquer primero, no lo entiende y hace en el Nuevo glosario una serie de consideraciones que nunca corrigió. Dice d'Ors de Bécquer, amén de otras cosas, las que siguen:

A pesar de cuanto pueda arbitrarse, perderá siempre a Bécquer, como poeta, la miseria de su instrumento verbal. Me refiero al de las Rimas - que no son rimas, y de ahí viene gran parte del mal, que no son rimas, sino coplas--: quizá el prosista de ciertas fantasías románticas salvárase mejor. Mientras que Rubén Darío es sinfónico - no siempre, confesémoslo, con buen gusto-, Bécquer es guitarresco -y guitarresco sin austeridad...- La abrumadora persistencia de las zapatilleras comodidades de la asonancia es algo que no pertenece al estílo popular y bronco, sino al burgués e isabelino, deteriora en Bécquer las gracias que de su sentimiento cabría esperar:

Gustavo Adolfo Bécquer: acordeón

tocado por un ángel ${ }^{27}$.

(Pienso que el acordeón es el último instrumento que cualquiera pondría en las manos de Bécquer).

Hay en esta interpretación de d'Ors muchas cosas: su cultura francesa, su no saber apreciar el tono becqueriano, pero, sobre todo, el que d'Ors había situado a Bécquer en el romanticismo y no sabía, no quería o no podía reinsertarlo de nuevo en nuestra literatura.

He aquí que, cuando Bécquer comienza a enseñorearse de la poesía española, en alas de la nueva poesía, su propia acuñada imagen, dividida, como hemos visto, en dos maneras distintas, impide al poeta instalarse en la modernidad. De tal modo que para defenderse de lo nuevo y para defender lo nuevo se utiliza a la misma persona, a Bécquer. Tanto Unamuno como d'Ors, pese a su indudable importancia y valía, no han comprendido la novedad que significa Bécquer, que los jóvenes poetas, por el portillo de Juan Ramón, ya han asimilado. Pero es que el Bécquer que aplauden Unamuno y d'Ors es el Bécquer primero, mientras que el Bécquer que sirve de bandera de la poesía española contemporánea es el Bécquer segundo. La novedad becqueriana, la nueva tradición

${ }^{27}$ D’Ors, Eugenio (1949), Nuevo glosario, Madrid, Aguilar, vol. III, pp. 418-419. 
lírica que supone, se basa, frente a lo que creía el crítico catalán, en sus procedimientos poéticos y en su instrumentación verbal; frente a lo que creía Unamuno no en lo pasional, sino en su distanciamiento pasional precisamente, y en su recuperación del pasado por medio de la memoria. Si la poesía española ha podido vivir lo que muchos llaman ya una segunda edad de oro, fue por abandonar la tradición petrarquista -iniciada en nuestra lengua por Garcilaso-e instalarse en la modernidad, en la tradición becqueriana, sustentada, como he venido manteniendo por Juan Ramón Jiménez.

Lo que nos queda de Bécquer no es un manojo de poemas más o menos amorosos, más o menos sentidos. Se trata de un nuevo modo de entender la poesía. Esa es, precisamente, su grandeza. 